\begin{tabular}{|l|l|l|}
\hline Received: Maret 2020 & Accepted: April 2020 & Published: April 2020
\end{tabular}

\title{
Pengaruh Persentase Massa Pasir Terhadap Tegangan Tekan (Compressive Stress) Pada Grass Block Lubang Lima Berbahan Sampah Plastik
}

\author{
Rolan Siregar* \\ Jurusan Teknik Mesin, Fakultas Teknik, Universitas Darma Persada, Jakarta 13450 \\ *corresponding author: rolansiregar@ft.unsada.ac.id
}

\begin{abstract}
The impact of piles of plastic waste on the environment is a very big problem in the Indonesia society such as water pollution, bad smell, and disturbed ecosystems. Processing plastic waste is a serious problem in Indonesia. This research will show a simple plastic waste processing but has a huge benefit, namely making grass blocks made from plastic waste. Grass block is a paving block that has a hole for grass growth which also functions to facilitate the absorption of rainwater into the ground. The grass block made is a five-hole grass block in the form that conforms to SNI standards. The specific purpose of this study was to determine the compressive stress of grass blocks made from plastic waste and the compressive stress of grass blocks made from a mixture of plastic waste with sand. This research method is experimental. Stages of the implementation of the research are made systematically starting from the study of literature, designing and manufacturing grass block printing machines, and ending is experimental compressive stress grass block. The results of this study indicate that the compressive stress of grass block made from full plastic waste is $18 \mathrm{MPa}$, and the maximum compressive stress of grass block made from a mixture of sand with plastic waste is $19.7 \mathrm{MPa}$ where the percentage of sand is $12,5 \%$. The amount of sand that exceeds $12,5 \%$ has a lower compressive stress. Based on the SNI standard the compressive stress of a paving block is at 9.8 MPa to 39.2 MPa. Then the test results show that the compressive stress of the grass block is within the SNI standard range. Therefore, this grass block development technology has an important role in reducing the adverse effects of plastic waste.
\end{abstract}

Keywords: plastic waste, grass block, waste processing, environmental pollution.

\begin{abstract}
Abstrak
Dampak tumpukan sampah plastik terhadap lingkungan menjadi masalah yang sangat besar di tengah masyarakat Indonesia seperti pencemaran air, aroma udara yang tidak sejuk, dan ekosistem yang terganggu. Pengolahan sampah plastik menjadi masalah yang serius di Indonesia. Penelitian ini akan menampilkan pengolahan sampah plastik yang sederhana tetapi memiliki manfaat yang sangat besar, yaitu pembuatan grass block berbahan sampah plastik. Grass block adalah paving block yang memiliki lubang untuk pertumbahan rumput yang sekaligus berfungsi untuk memudahkan penyerapan air hujan kedalam tanah. Adapun grass block yang dibuat adalah grass block lubang lima dengan bentuk yang sesuai standar SNI. Tujuan khusus penelitian ini adalah untuk mengetahui tegangan tekan grass block berbahan sampah plastik beserta tegangan tekan grass block berbahan campuran sampah plastik dengan pasir. Metode penelitian ini adalah dengan cara eksperimental. Tahapan pelaksanaan penelitian dibuat secara sistematis yang dimulai dari studi literatur, perancangan dan pembuatan mesin cetak grass block, dan diakhiri dengan pengujian tekan grass block. Hasil penelitian ini menunjukkan bahwa tegangan tekan grass block yang berbahan sampah plastik penuh adalah $18 \mathrm{MPa}$, dan tegangan tekan maksimum grass block berbahan campuran pasir dengan sampah plastik adalah 19,7 MPa di mana persentase pasir adalah 12,5\%. Jumlah pasir yang melebih 12,5\% memiliki tegangan tekan yang semakin rendah. Berdasarkan standar SNI tegangan tekan suatu paving block berada pada 9.8 s.d. 39.2 MPa. Maka hasil pengujian menunjukkan bahwa tegangan tekan grass block tersebut telah berada pada rentang standar SNI. Oleh karena itu teknologi pengembangan grass block ini memiliki peranan penting dalam mengurangi dampak buruk sampah plastik.
\end{abstract}

Kata kunci: sampah plastik, grass block, pengolahan sampah, pencemaran lingkungan 


\section{Pendahuluan}

Timbunan sampah yang ada di Indonesia menjadi permasalahan nasional yang harus dituntaskan secara bersinergi. Di mana jumlah timbulan mencapai 65.200.000 per tahun pada tahun 2016 dengan jumlah penduduk sebanyak 261.115.456 orang [1]. Maka timbunan sampah dapat dipastikan akan terus bertambah seiring dengan pertumbuhan penduduk dan perubahan gaya konsumsi masyarakat. Penelitian ini mengambil bagian dalam pengolahan sampah plastik menjadi produk grass block dengan nilai ekonomi lebih tinggi. Mengingat besarnya dampak buruk yang ditimbulkan oleh berbagai sampah seperti plastik yang sulit terurai maka penelitian ini sangat bermanfaat dan harus terus dikembangkan sampai produk komersial. Grass block adalah tipe paving block yang memiliki lubang sebagai tempat tumbuhnya rumput sekaligus bagian penyerapan air hujan. Produk ini digunakan pada area lintasan untuk pengeresan permukaan jalan, menghindari timbulnya lumpur, sebagai estetika halaman rumah, dan kemudahan untuk dibersihkan [2][3].

Sejumlah penelitian terdahulu telah banyak yang membahas bagaimana membuat paving block berbahan sampah plastik. Artikel [4] ini menampilkan pembuatan paving block berbahan campuran plastik, pasir sungai, dan zat pewarna (red oxide). Adapun tipe yang dibuat adalah bentuk solid, karena paving block ini mengandung plastik maka diperkirakan daya penyerapan air paving block tipe solid adalah sangat kecil sehingga kurang ramah lingkungan. Selanjutnya pada penelitian [5] membahas tentang daur ulang plastik dan fiber kelapa sebagai penguat pada paving block. Riset ini memiliki tujuan peningkatan kekuatan tekan paving block namun bahan fiber sabuk kelapa memiliki keterbatasan stock dan harga yang cukup mahal, sehingga komersialisasi produk akan lebih mahal juga, selain itu produk yang dibuat adalah tipe solid. Berbagai riset yang telah direview tentang pengolahan sampah plastik menjadi paving block adalah secara keseluruhan membuat tipe solid[6][7]. Pada kondisi tertentu seperti pada halaman rumah yang bukan merupakan daerah jelajah kendaraan bahwa tipe solid ini tidak ramah lingkungan karena persentasi daya serap air hujan sangat kecil. Maka pada penelitian ini ditampilkan pembuatan paving block tipe grass lubang lima yang bisa digunakan untuk halaman pekarangan dan sekaligus estetika sebagai tempat tumbuhnya rumput beserta ruang serapan air hujan.

Grass block pada umumnya terbuat dari beton, namun pada riset ini ditampilkan sebuah inovasi dimana grass block tersebut terbuat dari sampah plastik sebagai bahan utama. Untuk mencari mutu grass block yang lebih baik maka dilakukan rekayasa dengan pencampuran leburan plastik dengan pasir. Jumlah pasir yang optimal yang dimasukkan dalam satu proses pembuatan paving block merupakan bagian dari permasalahan penelitian ini. Grass block yang dicetak sesuai bentuk standar SNI dan pengujian tegangan tekan dilakukan di Laboratorium terstandar.

Secara umum penelitian ini dimaksudkan untuk mengurangi dampak pencemaran lingkungan akibat sampah plastik yang sulit terurai. Hal ini dicapai melalui proses pembuatan mesin press grass block berbahan campuran sampah plastik dengan pasir. Peleburan plastik dilakukan dengan memanfaatkan panas iron heater dan tungku gas. Tujuan khusus dalam penelitian ini adalah mengetahui kekuatan tekan grass block dengan bahan sepenuhnya sampah plastik, dan pengaruh persentasi campuran pasir dalam leburan plastik pada mesin cetakan terhadap kekuatan tekan (compressive stress). Dengan adanya penelitian ini diharapkan dapat berkontribusi secara akademik dalam pengembangan pengolahan sampah plastik di Indonesia.

\section{Metoda Penelitian}

\subsection{Tahapan Pelaksanaan}

Metode dalam penyelesaian masalah ini adalah dengan analisis eksperimental. Deskripsi pembuatan grass block dapat dilihat pada skematik Gambar 1 berikut. 


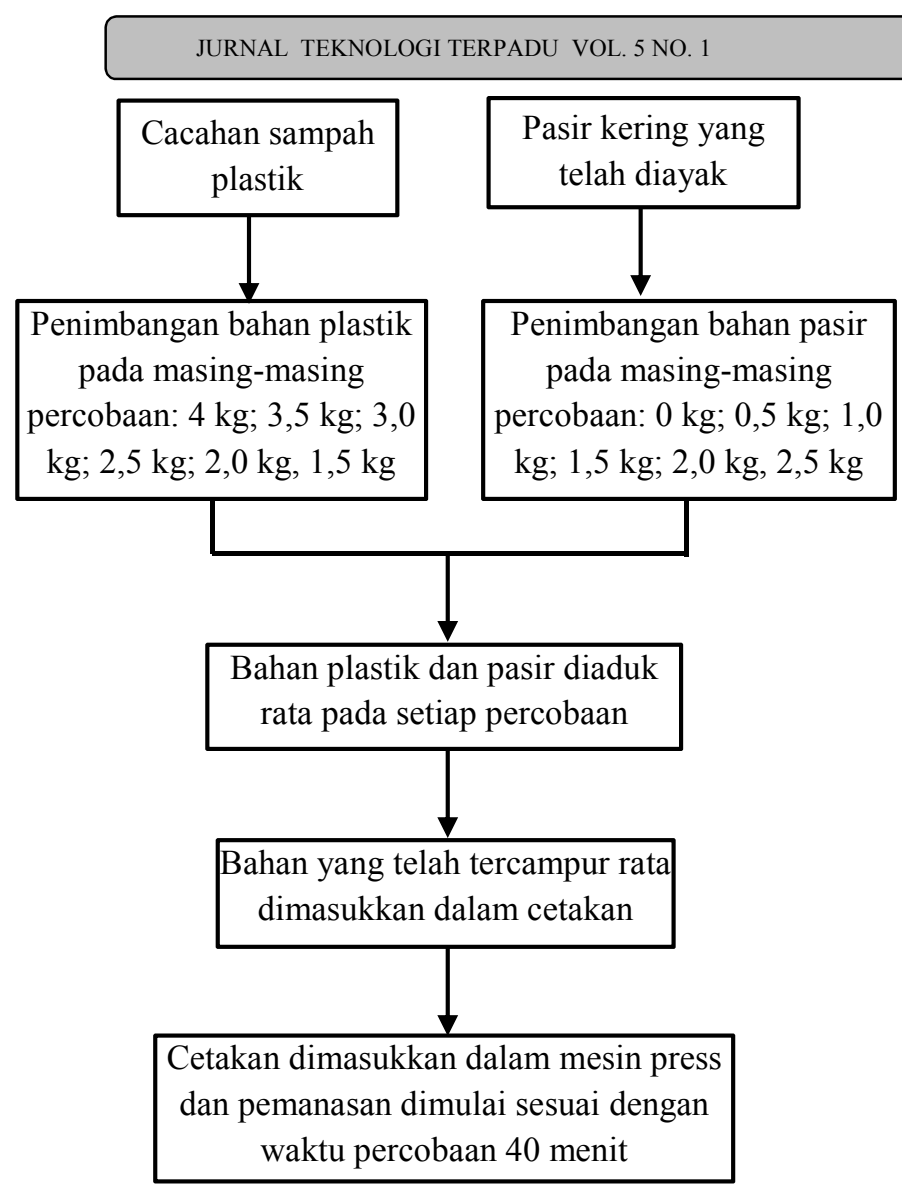

Gambar 1. Deskripsi proses pembuatan grass block

Deskripsi proses pembuatan grass block yang ditampilkan pada Gambar 1 dapat dijelaskan lebih rinci yaitu awal percobaan di mulai dari pengadaan plastik sampah yang telah dicacah untuk di daur ulang. Plastik yang tercacah ini ditimbang sesuai dengan ukuran yang telah diperhitungkan untuk setiap pengujian. Campuran plastik ini adalah pasir kering yang telah diayak. Perlakuan yang sama dilakukan yaitu dengan menimbang pasir sesuai dengan ukuran setiap kali percobaan. Adapun ukuran percobaan pertama adalah $4 \mathrm{~kg}$ plastik dicampur dengan $0 \mathrm{~kg}$ pasir, percobaan ke dua adalah $3,5 \mathrm{~kg}$ plastik dicampur dengan $0,5 \mathrm{~kg}$ pasir, percobaan ke tiga yaitu $3 \mathrm{~kg}$ plastik dicampur dengan $1 \mathrm{~kg}$ pasir, percobaan $\mathrm{ke}$ empat yaitu 2,5 kg plastik dicampur dengan 1,5 $\mathrm{kg}$ pasir, dan percobaan ke lima yaitu $2 \mathrm{~kg}$ plastik dicampur dengan $2 \mathrm{~kg}$ pasir, dan percobaan terakhir adalah $1,5 \mathrm{~kg}$ plastik dicampur dengan $2,5 \mathrm{~kg}$ pasir, maka dapat disimpulkan bahwa total massa setiap kali percobaan adalah $4 \mathrm{~kg}$.
APRIL 2020

ISSN $2338-6649$

Setelah pencampuran dilakukan dengan rata maka proses selanjutnya adalah penuangan ke cetakan grass block dan terakhir adalah pemanasan dan sekaligus pemadatan dalam mesin yang telah dibuat. Lama waktu pemanasan dalam tungku sampai plastik meleleh sempurna adalah 40 menit dengan besar temperature $200^{\circ} \mathrm{C}[8]$. Adapun mesin press yang telah dibuat adalah dalam skala prototipe. Harapan ke depan bahwa prototipe ini bisa dikembangkan menjadi mesin yang komersial yang dapat memproduksi grass block yang lebih bermutu.

\subsection{Desain Pengujian}

Mesin press grass block yang didesain mengacu pada mesin yang pada umumnya digunakan dalam industri [9], namun dalam mesin ini ditambahkan elemen pemanas untuk meleburkan plastik. Adapun elemen pemanas terdiri dari iron heater dan tungku api gas. Iron heater ini memiliki diameter $8 \mathrm{~mm}$ dan daya 900 Watt, dan tungku gas yang relatif besar dengan kapasitas tekanan tinggi dan diameter $18 \mathrm{~cm}$. Desain suatu mesin dibuat dalam bentuk CAD berbasis 3D untuk memudahkan revisi gambar supaya lebih optimal [10], [11].

Selain elemen heater dan tungku gas pemanas, elemen penyusun lainnya adalah tuas press untuk menekan plastik yang telah dicacah dalam cetakan sehingga lebih padat dan menghindari gelembung udara dalam grass block tersebut. Cerobong asap untuk mengurangi tekanan dalam ruang pemanas mesin akibat tingginya temperature elemen heater. Panel thermostat sebagai display temperature terjadi dalam ruang mesin sekaligus pengatur temperature yang diinginkan dalam mesin tersebut. Elemen cetakan merupakan cetakan grass block berlubang lima yang dibuat sedemikian rupa dengan berpasangan yaitu cetakan atas dan cetakan bawah. Adapun spesifikasi cetakan dibuat untuk grass block ukuran panjang $40 \mathrm{~cm}$ ,lebar $40 \mathrm{~cm}$, tinggi $8 \mathrm{~cm}$. Model desain mesin press ditampilkan dalam Gambar 2. 


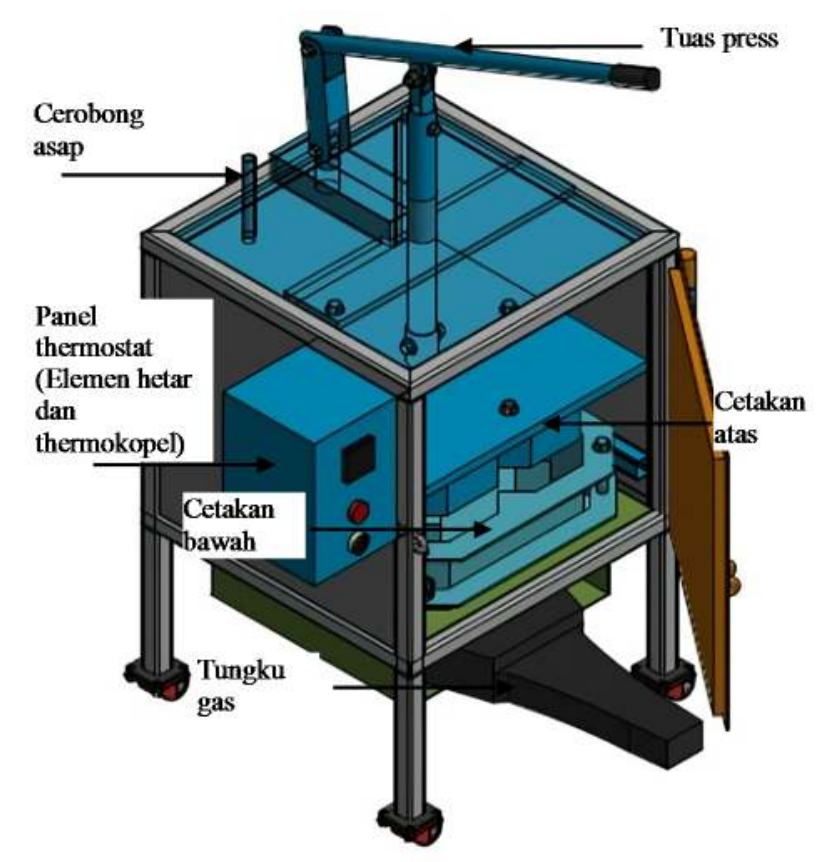

Gambar 2. Desain mesin press grass block

Pabrikasi setiap elemen harus optimal supaya menjadi satu kesatuan mesin press yang bersinergi dalam menjalankan fungsi masingmasing.

Pengujian compressive stress dilakukan dengan alat uji beton yang memiliki standar dan terkalibrasi yang ada di Unit Industri Bahan dan Barang Teknik, Dinas Perindustrian dan Energi DKI Jakarta. Sebagai model pengujian tegangan tekan dapat dilihat pada Gambar 3.

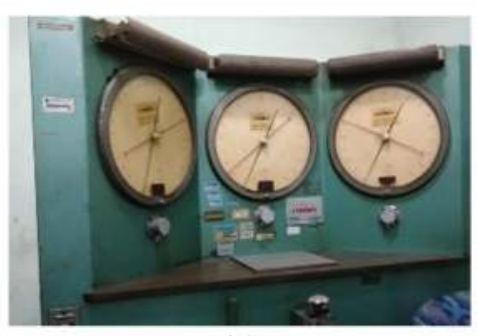

(a)

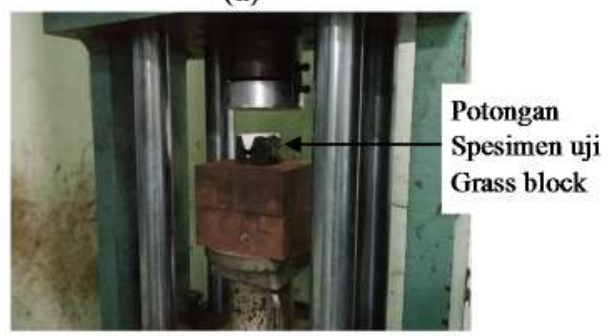

(b)

Gambar 3. Alat uji tegangan tekan; (a)- display alat uji, (b)- bagian utama alat uji.

Adapun cara pengujian dilakukan sesuai dengan SOP yang ada, seperti pada spesimen uji. Spesimen uji merupakan hasil pemotongan grass block untuk menyesuaikan dengan kapasitas elemen penekan. Untuk mendapatkan hasil uji yang optimal maka pada permukaan spesimen diberikan tepung gypsum supaya permukaan spesimen menjadi rata. Pengaruh pemberian gypsum ini sangat kecil sehingga besar tahanan gypsum dianggap mendekati nol.

\section{Hasil Penelitian}

\subsection{Hasil cetakan grass block}

Persentase jumlah pasir terhadap jumlah plastik akan mempengaruhi kualitas grass block tersebut. Besar komposisi masing-masing bahan pada setiap percobaan akan mendapatkan hasil kekuatan tekan yang berbeda-beda. Besar perbedaan tersebut hanya bisa diketahui setelah pengujian selesai dilakukan. Adapun jumlah percobaan pembuatan grass block sebanyak enam unit. Pada Tabel 1 berikut ditampilkan hasil pembuatan grass block. 
Tabel 1. Bentuk grass block lubang lima berbahan campuran plastik dengan pasir

\begin{tabular}{|c|c|c|c|c|c|c|}
\hline Item & 1 & 2 & 3 & 4 & 5 & 6 \\
\hline $\begin{array}{l}\text { Massa } \\
\text { Plastik, } \\
\text { kg }\end{array}$ & 4 & 3,5 & 3 & 2,5 & 2 & 1,5 \\
\hline $\begin{array}{l}\text { Massa } \\
\text { pasir, kg }\end{array}$ & $0(0 \%)$ & $0,5(12,5 \%)$ & $1(25 \%)$ & $1,5(37,5 \%)$ & $2(50 \%)$ & $2,5(62,5 \%)$ \\
\hline foto & & & & & & \\
\hline
\end{tabular}

Dari Tabel 1 dapat dijelaskan bahwa pengujian nomor satu adalah bahan plastik sepenuhnya dengan total massa $4 \mathrm{~kg}$, secara visual hasil cetakan ini relatif padat. Pengujian nomor 2 dilakukan dengan penambahan pasir $0,5 \mathrm{~kg}(12,5 \%)$ sehingga massa plastik $3,5 \mathrm{~kg}$, di mana hasil cetakan terlihat padat dan padu antara pasir dengan plastik. Pengujian nomor 3 yaitu dengan penambahan pasir $1 \mathrm{~kg}(25 \%)$ sehingga massa plastik $3,0 \mathrm{~kg}$, sama halnya dengan nomor dua di mana hasil cetakan terlihat padat dan pasir dengan leburan plastik adalah padu. Pengujian nomor 4 dengan komposisi pasir 1,5 $\mathrm{kg}(37,5 \%)$, plastik $2,5 \mathrm{~kg}$, hasil cetakan padat dan terlihat pasir sudah mulai muncul dalam permukaan yang tidak lengket. Pencetakan grass block nomor 5 dengan komposisi pasir $2 \mathrm{~kg}(50 \%)$, plastik 2,0 $\mathrm{kg}$, secara visual hasil ini sudah keropos karena pasir banyak yang tidak terikat dengan lelehan plastik, untuk uji laboratorium tegangan tekan pada spesimen ini tidak memungkinkan lagi. Pengujian nomor 6 dengan komposisi pasir 2,5 $\mathrm{kg}(62,25 \%)$, plastik 1,5 kg, hasil pengujian ini menampilkan bahwa pasir dengan plastik sudah tidak bisa padu, karena komposisi pasir telah terlalu banyak sehingga lelehan plastik tidak sanggup mengikatnya.

\subsection{Tegangan Tekan (Compressive Stress)}

Pengujian tegangan tekan dilakukan untuk mengetahui performa paving block berbahan sampah plastik, untuk menjadi pertimbangan kelayakan produk [12]. Pengujian tekan dilakukan pada sepesimen yang secara kualitatif padat dan kuat yaitu spesimen hasil pencetakan nomor 1 s.d. 4, karena spesimen nomor 5 tidak memungkinkan lagi diuji laboratorium karena terlihat rapuh dan keropos. Spesimen nomor 6 tidak terbentuk menjadi grass block karena pasir dengan leburan plastik tidak menyatu sehingga otomatis tidak dilakukan pengujian compressive stress. Spesimen uji nomor 1 (pasir $0 \%$ ) diperoleh tegangan tekan sebesar 18,0 $\mathrm{MPa}$ ), spesimen nomor 2 (pasir 12,5\%) diperoleh tegangan tekan sebesar 19,7 $\mathrm{MPa}$, spesimen nomor 3 (pasir $25 \%$ ) diperoleh tegangan tekan sebesar 17,2 $\mathrm{MPa}$, dan spesimen nomor 4 (pasir 37,5\%) diperoleh tegangan tekan sebesar 9,9 MPa. Untuk melihat perbandingan tegangan tekan maka lebih mudah dilihat dalam bentuk grafik. Pada Gambar 4 ditampilkan hasil uji laboratorium compressive stress pada spesimen 1 s.d. 4 tersebut. 


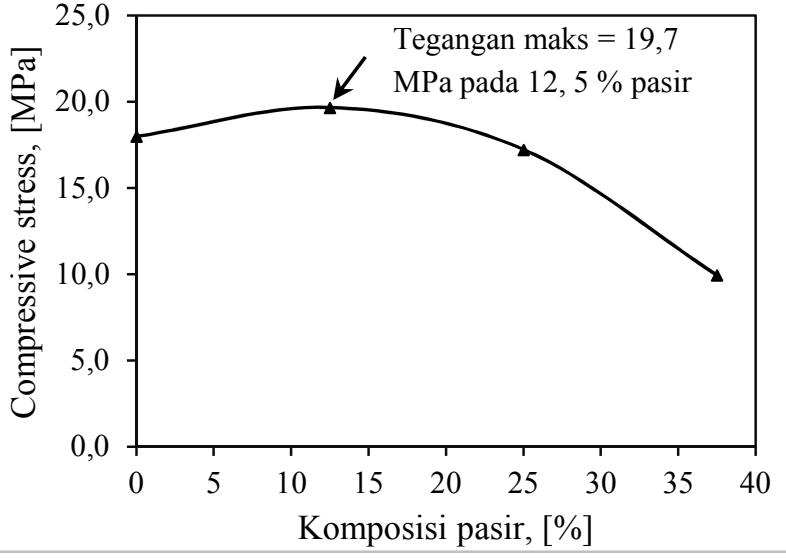

Gambar 4. Grafik tegangan dengan persentase pasir

Dapat dijelaskan bahwa tegangan tekan grass block maksimum pada komposisi pasir $12,5 \%$ yaitu 19,7 MPa. Hal ini bisa terjadi karena pasir dalam leburan plastik dengan jumlah yang ideal dapat mengurangi cacat gelembung udara dalam grass block, sehingga spesimen ini lebih padat dan lebih kuat. Akan tetapi kekuatan tekan grass block dengan komposisi pasir yang melebihi ideal akan mengurangi tegangan tekan (compressive stress) spesimen tersebut. Tegangan tekan suatu paving block berdasarkan SNI adalah sekitar 9,8 s.d. 39,2 $\mathrm{MPa}$, semakin tinggi nilai tegangan tekan maka mutu produk semakin tinggi. Tegangan tekan spesimen grass block yang dihasilkan dalam riset ini adalah 19,7 $\mathrm{MPa}$ sehingga sudah termasuk dalam standar SNI dengan kualitas menengah.

\section{Kesimpulan}

Berdasarkan hasil penelitian maka dapat disimpulkan beberapa hal yaitu tegangan tekan (compressive stress) pada grass block berbahan plastik yang sepenuhnya adalah $18 \mathrm{MPa}$, sedangkan tegangan maksimum grass block berbahan campuran pasir dengan leburan plastik adalah 19,7 MPa dengan komposisi pasir $12,5 \%$. Tegangan tekan pada komposisi pasir yang melebih 12,5\% adalah semakin menurun, bahkan pada persentase pasir sebesar $50 \%$ dan $62,5 \%$ tidak dilakukan uji tegangan tekan lagi karena bentuk secara kualitatif sangat rapuh dan keropos. Maka dengan komposisi pasir dan leburan plastik yang ideal akan menghasilkan tegangan tekan grass block yang lebih tinggi, bentuk yang lebih padat, dan permukaan yang lebih rata.

\section{Daftar Pustaka}

[1] P. A. Safitri, W. S. Purba, and M. Zulkifli, Statistik Lingkungan Hidup Indonesia 2018: Pengelolaan Sampah di Indonesia. Jakarta: Badan Pusat Statistik, 2018.

[2] B. Kaviya, "A study on compressive strength of paving blocks prepared with stone crusher dust and flyash," J. Chem. Pharm. Sci., vol. 9, no. 2, pp. E125-E129, 2016.

[3] G. Navya and J. V. Rao, "Experimental Investigation on Properties Concrete Paver Block with the Inclusion of Natural Fibers," J. Eng. Res. Appl. www.ijera.com, vol. 4, no. 8, pp. 34-38, 2014.

[4] D. Sellakutty, D. A, and K. K, "Utilisation of Waste Plastic in Manufacturing of Bricks and Paver Blocks," Int. J. Appl. Eng. Res., vol. 11, no. 3, pp. 364-368, 2016.

[5] M. Achitra, R. A. Rajasree, R. V. Pandit, and V. Saranya, "Recycled Plastic and Coconut Fibre used in Concrete Paver Block," Int. J. Eng. Sci. Comput., vol. 8, no. 4, pp. 1682716830, 2018.

[6] A. Kumi-Larbi, D. Yunana, P. Kamsouloum, M. Webster, D. C. Wilson, and C. Cheeseman, "Recycling waste plastics in developing countries: Use of lowdensity polyethylene water sachets to form plastic bonded sand blocks," Waste Manag., vol. 80, pp. 112-118, 2018.

[7] J. Ghuge, S. Surale, B. M. Patil, and S. B. Bhutekar, "Utilization of Waste Plastic in Manufacturing of Paver Blocks," Int. Res. J. Eng. Technol., vol. 06, no. 04, pp. 19671970, 2019. 
[8] R. Siregar, "Korelasi Besar Temperatur Pemanasan Cetakan terhadap Kualitas Hasil Press Paving Block Berbahan Dasar Sampah Plastik," FLYWHEEL J. Tek. Mesin Untirta, vol. V, no. 1, pp. 41-45, 2019.

[9] N. B. Sriyanto, S. Ariyono, H. Saptono, and A. Pendahuluan, "Rancang Bangun Mesin Pencetak Paving Block Dengan Sistem Vibrator Untuk Meningkatkan," DIANMAS, vol. 3, no. 1, pp. 53-58, 2014.

[10] R. Siregar, F. Zainuri, and M. Adhitya, "Design a New Generation of Synchromesh Mechanism to Optimization Manual Transmission's Electric Vehicle," in Proceeding of the 15th International Conference on QIR (Quality in Research) ISSN, 2017, vol. 1411, p. 1284.
[11] R. Siregar, M. Bur, and S. Huda, "Perkiraan Kekuatan Struktur Mekanik Side Scraper dengan Metode Elemen Hingga Beserta Rekomendasi Material Pengganti Elemen Kritis," ROTASI, vol. 21, no. 4, pp. 251-257, 2019.

[12] M. Ali Ahmed and B. Singhi, "Overview on structural behaviour of concrete block pavement," Int. J. Sci. Eng. Res., vol. 4, no. 7, pp. 782-789, 2013. 